\title{
The Complexity of Transdisciplinary Literature Reviews
}

\author{
ALFONSO MONTUORI \\ California Institute of Integral Studies (USA)
}

The transdisciplinary literature review is an opportunity to situate the inquirer in an ecology of ideas. This article explores how we might approach this process from a perspective of complexity, and addresses some of the key challenges and opportunities. Four main dimensions are considered: (a) inquiry-based rather than discipline-based; (b) integrating rather than eliminating the inquirer from the inquiry; (c) meta-paradigmatic rather than intra-paradigmatic; and (d) applying systems and complex thought rather than reductive/disjunctive thinking.

\section{Introduction}

In his critique of disciplinarity, Gordon (2006, p. 4) writes that:

The emergence of disciplines has often led to the forgetting of their impetus in living human subjects and their crucial role in both the maintenance and transformation of knowledge-producing practices. The results are a special kind of decadence. One such kind is disciplinary decadence. Disciplinary decadence is the ontologizing or reification of a discipline. In such an attitude, we treat our discipline as though it was never born and has always existed and will never change or, in some cases, die. More than immortal, it is eternal. Yet as something comes into being, it lives, in such an attitude, as a monstrosity, as an instance of a human creation that can never die. Such a perspective brings with it a special fallacy. Its assertion as absolute eventually leads to no room for other disciplinary perspectives, the result of which is the rejection of them for not being one's own. Thus, if one's discipline has foreclosed the question of its scope, all that is left for it is a form of "applied" work. Such work militates against thinking.

In this essay I explore some of the dimensions of transdisciplinarity and complexity in the specific context of a literature review. I focus specifically on addressing the disciplinary decadence Gordon discusses, drawing on the work of Morin, Nicolescu, Wilshire, and others (Morin, 2008a, 2008b; Nicolescu, 2002; Wilshire, 1990). Transdisciplinarity is a fundamentally different way of approaching and organizing knowledge. It does not start with isolated atoms of information, which can serve as the individual bricks that make up edifice of knowledge. In a transdisciplinary approach, 
knowledge is seen as a vast web of relationships that are interconnected and form a larger ecology of ideas (Fabbri \& Munari, 1984; Morin, 1991).

I have suggested that transdisciplinarity inquiry can be thought of as having four main dimensions (Montuori, 2005a, 2010). These are: 1) Inquiry-based rather than discipline-based; 2) integrating rather than eliminating the inquirer from the inquiry; 3 ) meta-paradigmatic rather than intra-paradigmatic; and 4) applying systems and complex thought rather than reductive/disjunctive thinking.

\section{The complexity of inquiry}

Transdisciplinarity is inquiry-driven rather than discipline-driven: This first dimension is about the focus of our work. In transdisciplinarity, scope is defined by the needs of the subject matter, not determined and guided by the parameters of the discipline. Traditionally, academic inquiry has approached all phenomena from the perspective of a single discipline. If we are psychologists, then we might study the psychology of creativity, or leadership. If we are sociologists, we might study the sociology of work or gender.

Bruce Wilshire's important book "The moral collapse of the university" (Wilshire, 1990) discusses how traditional disciplinary education has created and maintained rigid disciplinary boundaries. Wilshire specifically illustrates the process of disciplinary "purification" through which disciplines have kept extra-disciplinary influences at bay, despite efforts by some to argue for inter- or cross- or even trans-disciplinary work. In this way, disciplinary purification paralleled the purification of variables from exogenous factors, under the assumption that laboratory conditions of isolation that could achieve this purification were in fact the ideal conditions for experimentation and understanding (Ceruti, 1994). Here we see a theme I will return to, namely the fractal nature of the organization of knowledge. We see certain principles recurring at a number of different system levels: from the way knowledge is organized in and by an individual's thinking, to the way the same principles show up in the organization of institutions of learning.

Disciplinary approaches have historically produced some excellent research, but they are also limited and limiting. If we want to understand a particular leader, approaching her from an exclusively through the discipline of psychology would mean looking at say, personality traits or cognitive style. But, as cognitive scientist Howard Gardner has explicitly done in his books on creativity and leadership for instance, it would also mean leaving out the larger context, relationships, institutions, events, and more (Gardner, 1994, 1995). The problem is not that such research is not interesting or important per se, but that it gives us a partial view, and this view is often - despite warning labels - taken to be the whole. Using that partial view as a lens through which to view the entire phenomenon becomes problematic, particularly for practitioners. Unlike academic disciplines, life does not break down into neat categories and disciplines, and we ignore them at our own risk.

In the approach to transdisciplinary inquiry I am proposing we begin with the phenomenon, develop a rich description through a narrative, ask questions, and then learn where we might find relevant information, based on what arises as we begin our exploration and description of our topic. This narrative description also allows the reviewer to point out why a discipline-driven review would be insufficient and ground that decision through a description of the phenomenon that highlights the areas that would remain obscured by a disciplinary review. What is the phenomenon we are seeking to understand, and what aspects of our description would need to be sacrificed in a discipline-driven inquiry? How are the elements of the narrative interconnected, and how do their interconnectedness and the multi-dimensionality of the phenomenon require a transdisciplinary approach? 
One of the frequent problems doctoral students face in formulating a research topic is a tendency to lose touch with events and people as they enter the rich landscape of theoretical perspectives and methods. Grounding the research in events and people helps to bring it back to something happening in the world involving people somewhere. This description requires a complexity-based approach (Morin, 2008a), as the focus is not on isolating the single most important variable but in describing a network of interconnected events, individuals, and relationships. This leads us to the second dimension, the organization of knowledge.

\section{Thinking complexity}

Traditionally, we are taught that the organization of knowledge occurs through disjunction and reduction (Alhadeff-Jones, 2008, 2010; Morin, 2008a, 2008b). These processes are intrinsic to the process of purification and isolation of variables, and developing Descartes's clear and distinct ideas (Descartes, 1954). This approach is focused on the centrality of simplicity. Knowledge becomes increasingly specialized, as we eliminate the material we think is not relevant for our inquiry. We typically confine our inquiry to our discipline, and eliminate any other exogenous factors or exogenous sources. In fact, anything that does not fit into our disciplinary lens is often not even seen or acknowledged (Montuori \& Purser, 1999a). The topic's identity is achieved through reduction and disjunction: Ideally we reduce a question to one or two variables. So the way we think is crucial, and there is a clear tradition in the West and in academia about what is considered "good thinking." This includes "clear and distinct ideas," definitions, and the logic of Aristotle (binary, either/or, logic of identity, A/not-A, the excluded middle) (Morin, 2008a, 2008b; Wilden, 1980). This kind of thinking has had enormous influence, importance, and effectiveness. It's also limited, particularly when we want to understand relations, interactions, contexts, and networks, because they are precisely what this kind of thinking and this kind of organization of knowledge was designed to eliminate.

Transdisciplinarity draws on systems and complexity theories to propose a way of thinking that is different from reductive/disjunctive disciplinary thought. It requires a kind of thinking that contextualizes, starting with the assumption that any system needs to be understood in terms of its larger environment and relationships, and connects, showing how to bring the information from separate disciplines together so that it can be useful knowledge that allows us to act wisely (Flyvbjerg, 2001).

In the literature review, this process of contextualization becomes vital. Contextualization here refers to plural contexts: the development of ideas in the context of time; the development of a plurality of ideas complementary, antagonistic, or concurrent (Morin, 2008a), and the contexts of their different intellectual and theoretical traditions; the development of the inquirer's or reviewer's interest in and perspectives on the topic or what the reviewer brings to the table (in the case of dissertation research, this would of course include the dissertation topic).

There is an isomorphism between what Morin calls the reductive/disjunctive 'simple thought' that has characterized much of Western history, and the disciplinary organization of knowledge in educational and research institutions (Montuori, 2008, 2010). In his Discourse on method (originally published in 1637), Descartes (1954) explored what he held to be the basic laws of thinking, and fashioned them into a methodology for inquiry. Below are two key points Descartes made under the telling heading of Rules for the direction of the mind, an unfinished treatise, published originally in 1701:

\section{RULE V}

The method consists entirely in the orderly arrangement of the objects upon which we must turn our mental vision in order to discover some truth. And we shall be observing 
this method exactly if we reduce complex and obscure propositions step by step to simpler ones, and then, by retracing our steps, try to rise from the intuition of all of the simplest ones to knowledge of all the rest. (Descartes, 1954, p. 157)

\section{RULE XIII}

If we are to understand a problem perfectly, we must free it from any superfluous conceptions, reduce it to the simplest terms, and by process of enumeration, split it up into the smallest possible parts. (ibid., p.179)

What Descartes proposed as rules for the direction of mind has been institutionalized in the organization of universities. There we find the same increasing specialization in departments, splitting knowledge up into smallest possible parts, and the creation of strong boundaries based on three axioms of classical logic (Nicolescu, 2002).

This fragmentation/separation technically excludes the possibility of already existing sub-disciplines, and a host of hyphenated hybrids, or for that matter Cognitive Science or Neuroscience. That these hybrid sub-disciplines have emerged is a testament to the need to break out of existing disciplinary boundaries. But we also have to recognize that in many cases the disciplinary boundaries of the new system are closed, and essentially a new closed disciplinary system is created. Research conducted in the sub-disciplines that have emerged, such as Political Psychology or Cross-cultural Psychology, is often published in the dedicated new journal, usually with a title like "Journal of the Newly Minted Sub-Discipline," and usually remains there without having an impact on the wider discourse. The sub-discipline operates in isolation, and the system of disciplinary fragmentation (Alhadeff-Jones, 2008; Becker, 1976) continues, becoming a closed system with strong boundaries that defines its identity. Women's Studies and Cultural Studies are examples of inherently inter- or multi-disciplinary areas of study that nevertheless, in the process of disciplinarization, risk becoming isolated in their own sphere rather than having an impact on the wider discourse.

A transdisciplinary literature review can shed light on the way that a certain way of thinking and framing inquiry can obscure aspects of existence, how these frames are informed by deeper assumptions that shape the inquiry and consequently determine what is relevant and what is not relevant, what is important and what not important, and how habits of mind such as disjunctive thinking can predispose us to separate and isolate what is in fact related and recursive or co-creating. Thinking that is informed by a binary logic is faced with an uphill struggle when considering the possibility of both/and, relational thinking. The disjunctive, binary logic can prevent some thoughts from being thought, and some possibilities entertained. In the same way, disciplinary fragmentation is not simply a division of labor that helps us to address the increasingly overwhelming amount of knowledge that is being generated. Disciplinary fragmentation is not just a response to knowledge: it actually frames knowledge. It is a way of organizing knowledge by making distinctions, including distinctions (often implicit) about what is and is not knowledge. And because the sub-systems of the larger system of disciplinary knowledge are mostly closed systems, disciplinary fragmentation creates blind spots by framing the world in a discipline-driven way that actually prevents certain subjects from being 'seen'.

The transdisciplinary researcher follows Pascal's maxim that one must know the parts in order to know the whole, and the whole in order to know the parts. In other words, a transdisciplinary view, informed by systems and complex thought, addresses the larger whole, the context, the relationships and interactions, and the many dimensions or system levels that emerge in the process - whether the brain, individual person, group, community, nation, and the global context. The task - and art - of transdisciplinary research, is to assess to what extent these different system levels are sources of pertinent information. 
Transdisciplinary research therefore also requires a new way of learning that is more open to complexity and networks. Morin and Kern (1999, p. 130) rightly state that:

We need a kind of thinking that relinks that which is disjointed and compartmentalized, that respects diversity as it recognizes unity, and that tries to discern interdependencies. We need a radical thinking (which gets to the root of problems), a multidimensional thinking, and an organizational or systemic thinking...

There are clear implications for practice. Say we are interested in fostering creativity in education, now that a video gone viral has informed us that schools kill creativity (Robinson, 2001). A traditional reductionist approach focuses on the single most important variable or system level, which would be one system and one system only, whether the individual student, or the classroom, or the economics of the school. Psychology has traditionally led us to study individual students, and their personalities or cognitive processes. Complex thinking, after developing a rich picture of the phenomenon looks at the interrelationship between the various systems we have selected as being of particular significance. Rather than focusing exclusively on the students' cognitive capacities for creativity through testing, for instance, the more expanded, contextual approach of complexity thinking might look at any number of factors from classroom size and pedagogy to the role home environment. From a traditional perspective such an approach brings in many more variables and is therefore not just complex but complicated and difficult precisely because there are many new factors to contend with. Not addressing this complexity, on the other hand, is also very problematic. While we keep in mind the problems inherent in such an ambitious approach, we also recognize the necessity for epistemological humility and strategies of inquiry that elicit the creativity of the inquirer.

The stress on selecting interactions among systems of greatest relevance, makes the constructive and creative dimension, the distinctions made by the inquirer, particularly obvious. Any such effort would view students' activities within the larger contexts of the classroom, the school, the family, neighborhoods, regional and government policy, and so on. But in our multi-dimensional understanding of these larger (supra-) systems, we constantly refer back to the experience and interaction of individual students, cohorts, schools, and so on.

On the basis of this system of relationships we would then explore what Morin calls the pertinent literature (Morin, 2008a, 2008b). As we saw in the discussion of the first dimension, this means developing a rich picture of the system in question, and creating a useful system definition (Banathy, 1973). We begin therefore with a rich description of our phenomenon, a narrative description. Out of the narrative we develop, through an ongoing reflection, a "core description" of our topic - the key question, which of course is open to ongoing revision. On the basis of the description and the question, we assess and explore pertinent research literatures. The literature review is then focused on this key question that acts as a central node or attractor.

Transdisciplinary research and the transdisciplinary literature review can be particularly overwhelming because there appears to be, and often is, so much material to address, and it is scattered in so many different fields. With the emergence of new technology it is, of course, so much easier to have access to journals and dissertations that once gathered dust on library shelves. At the same time, this information has to be assessed and organized. As Morin has written (Morin, 2008a), one of the key problems of our times is not so much the generation of knowledge but the organization of the overwhelming quantity of knowledge we have access to.

We have to navigate our processes of divergence and convergence, the tendency to dispersion that follows going down too many interesting side-roads, and the tendency to premature closure and converging too soon, missing the opportunity to draw on other 
relevant sources of data and insights. This skill develops with practice and experience, but remains an ongoing challenge.

I have found it important to 'ground' the initial framing through the identification and narration of a core research question, specifically in the context of doctoral research to frame it as an invitation to see it and articulate it in quite instrumental terms: what am I going to be an expert in, and how can I explain my topic simply and briefly so a layperson can understand it? The term 'expert' should be briefly addressed because there is a popular misunderstanding that being a transdisciplinary scholar means having no specialization. In other words, one allegedly and suspiciously knows everything about everything, and is not confined to being a historian, or a sociologist. In fact transdisciplinarity is an approach to inquiry that would situate us not in a discipline, but as specialized in, or researchers of, one or more topics. This brings us back to the first distinction, that transdisciplinarity is inquiry-driven, not discipline-driven.

It is possible that in our choice of topic we may have stumbled on a topic about which there is not a lot of research. In that case, we can step back and look at the larger ecology in which the topic is embedded. We view the topic as a subsystem of larger systems, and scale up. As an example, the potentially beneficial psychological effects of cross-cultural encounters (Montuori \& Fahim, 2004) have historically been underresearched. While the notion that travel can somehow change us, broaden our perspectives, and even lead to psychological growth, was discussed in novels and among travelers, the research itself was minimal, with one key article published and interestingly regularly reprinted, but with no follow-up (Adler, 1975). The core issue therefore was travel as an opportunity for personal growth. Even though this specific positive frame (personal growth) was largely absent from the discourse on travel and cross-cultural experience, which was situated in the larger field of cross-cultural psychology. Cross-cultural psychology was what I call the Dominant Disciplinary Discourse or DDD (Montuori, 2005a). The DDD is the disciplinary discourse where most if not all of the work on our topic has been done. If little or no work has been done on our topic, then we look for where the work with the most 'family resemblance' has been done - in this case, cross-cultural psychology. While most of the social science work on cross-cultural encounters and their psychological effects had been done here, the theoretical frameworks used focused on addressing pathology - avoiding or minimizing culture shock.

In working with a topic on which there appears to be little or no research, therefore, one strategy is to scale up, as if we were drawing a series of expanding concentric circles around our topic, but situating it clearly in one DDD, which allows us to explore the disciplinary assumptions and the limitations of its theoretical frameworks, in the same way that the dominant theoretical frameworks applied to culture shock and more generally cross-cultural encounter did not account for the possibility of personal growth.

We survey the literature in order to explore a question that emerges from, and is grounded in, experience. We can then begin to see how to step back and assess the larger framing of the topic. In the case of cross-cultural encounter, the literature could survey what little there was on this topic, what the other literature on cross-cultural encounter consisted of in terms of broad theoretical frameworks (medical, social psychological, etc.) and then how they did not allow for the possibility of personal growth, as we all as brief discussion of theoretical frameworks that did incorporate the possibility of personal growth. A transdisciplinary literature review therefore explores how various theoretical frameworks shape our understanding of a topic, and inevitably both illuminate some aspects while obscuring others. 


\section{The inquirer and the inquiry}

The next dimension of transdisciplinarity integrates the inquirer in the inquiry. As we saw above, this means that knowing is viewed as a creative, constructive process, a process of distinction, selection, foregrounding, hierarchizing, discarding, connecting (Maruyama, 1974; Montuori \& Donnelly, 2013; Morin, 1991). Any review of the literature, from this perspective, is a creative construction. The reviewer chooses what to include, what to give importance to, how it is presented, and so on. We might think that a simple list of 'who said what when' somehow eliminates this problem, that it creates a 'level playing field' that somehow prevents this irruption of subjectivity, of 'choices' that reflect the writer/reviewer's 'bias.' But we make choices all the time, of course, including choices to write a literature review like a laundry list. And the choices extend to which authors we put first or whether we put them in alphabetical or chronological order, how much space we give them, and of course what we say about them. It also includes a reflection on how various works have been critiqued, why, and by whom, and ultimately how we interpret and evaluate these critiques. Integrating the inquirer into the inquiry, the reviewer into the review, means more than just using the literature review to situate oneself in the discourse. It also means taking responsibility for the creative constructive process that is the organization of knowledge.

Transdisciplinarity is not about abstract knowledge, but about knowledge that is embodied and embedded. The integration of the inquirer into the inquiry - and the reviewer in the review - is about the engagement of knowledge. It therefore recognizes that with knowledge there is always a knower, and that the knower actively constructs her or his understanding of knowledge, from a specific point of view. Understanding this creative and creating knower through self-inquiry and dialogue with others becomes an integral aspect of the process. It is important to understand the matrices through which each one of us constructs his or her understanding of the world (Ceruti, 1994). Once we realize that subjectivity cannot be eliminated but is an integral part of our knowledge, we can begin by making our underlying assumptions explicit. This can happen through self-inquiry, through exchanges with others in a learning community, and with the authors in the texts we are discussing.

Understanding ourselves as knowers means seeing ourselves as nodes in a network, part of a larger ecology of ideas, as well as a sociopolitical and cultural context. In order to do this, we have once again to think systemically, to think through the complexity of the web we are woven into. What is our relationship to knowledge (Fabbri \& Munari, 1990)? To our ideas (Morin, 1991)? We may have ideas, but what ideas have us? Who and what inform our thinking, our identification and framing of a problem? Who are our influences? What traditions have influenced us? What are our goals, biases, tendencies, and proclivities? How do we - as authors - make our mark on the review that is our creation (Montuori, 2005b)? Instead of attempting to eliminate the researcher from the research process, a transdisciplinary approach encourages transparency instead, an ongoing process that is achieved through a constant self-inquiry, self-assessment, and really a practice of scholarly self-development, questioning our own assumptions, our beliefs, our investment in one or another outcome, in being right, and so on.

Another key aspect is the dialogue with the literature, which helps to situate the inquirer in the context of the research. Particularly in the case of literature reviews preceding original research, the reviewer's perspective is contextualized, articulated, and refined in dialogue with the material being reviewed. The reviewer can assess, review, and critique the material, thus presenting her or his perspective on the material, identifying (or not) with major and minor streams of thought, existing positions, and so on. The important point here is the active, engaged participation in the dialogue, so that the reviewer is no longer a bystander to inquiry and to the discourse, but a participant. 


\section{The paradigmatic dimension}

The fourth dimension of transdisciplinarity explores the construction of knowledge. Situating ourselves in the literature does not, in this perspective, simply mean giving a sense of the landscape. It means recognizing that every contribution we are referencing and discussing is also a creative, constructive attempt to contribute to the discourse. Any such work is itself situated in a larger ecology, draws on certain perspectives, certain angles of approach, and reflects certain viewpoints and traditions. The same is true for the reviewer, of course. The paradigmatic dimension of transdisciplinarity is radical, therefore, in the sense that it goes to the roots of the flora found in our ecology of ideas.

Transdisciplinarity is meta-paradigmatic rather than intra-paradigmatic. Most researchers working within a specific discipline take the discipline's 'paradigmatic assumptions' for granted. They work within - intra - these central assumptions that constitute the larger paradigm. Most psychologists don't lose too much sleep over the fact that their unit of analysis is almost always the individual, not the group or culture or society etc. Nor are most scholars particularly concerned with their epistemological stance. They just get on with it, in the same way that most physicists get on with their research agenda and do not spend too much time wondering about the implications of what Erwin Schrödinger called diese verdammte quantumspringerei, or that damned quantum jumping, no matter how fascinating it is and how much attention it has received in works of popular science.

We recall Lewis Gordon's warning about the dominance of a single discipline at this point (Gordon, 2006, p. 4):

Its assertion as absolute eventually leads to no room for other disciplinary perspectives, the result of which is the rejection of them for not being one's own. Thus, if one's discipline has foreclosed the question of its scope, all that is left for it is a form of "applied" work. Such work militates against thinking.

Transdisciplinary research draws on a plurality of disciplines in an attempt to address the complexity of phenomena. But does that mean we need to know everything about every discipline you're using? No. But we can begin to understand how the different disciplines and perspectives we're drawing on are shaped by different paradigmatic assumptions.

Transdisciplinarity focuses on the way knowledge is constructed. How does a particular disciplinary perspective construct its understanding of its subject matter? In my courses on transdisciplinarity I have used an edited volume on Social Creativity (Montuori \& Purser, 1999b). Students are invited to see how scholars in a number of different disciplines (philosophy, anthropology, various branches of psychology, evolutionary biology, etc.) construct their understanding of the social dimensions of creativity. The results are very different, informed by the authors' disciplinary and paradigmatic assumptions. The contributions range from a hermeneutic history of the concept of imagination in philosophy (Kearney, 1999) to the relationship between the Biblical creation story and the Western image of the lone genius (Barron, 1999), the interaction of Romanticism and consumerism (Stigliano, 1999), and the childhood and educational experiences of eminent creative individuals (Mockros \& Csikszentmhalyi, 1999). The point is to explore how these different scholars constructed their understanding of creativity addressing the same fundamental topic based on different starting points with different assumptions. Dean Keith Simonton illustrates how psychologists and sociologists/anthropologists constructed very different understandings of creativity, based on different assumptions, most obviously that for the former the individual is the unit of analysis, and for the latter, society as a whole (Simonton, 1999). In this way, students can begin to see the creativity inherent in the construction of perspectives, interpretations, and frameworks to approach a topic. 
In an excellent article, Glaveanu has systematically shown how different philosophical perspectives inform the different approaches to creativity and the major trends in current creativity research (Glaveanu, 2010). His article is a good example of how these kinds of systematic and metaparadigmatic reviews. Paradigmatic assumptions can be seen in the way inquirers address key dimensions such as ontology (e.g., atomism vs. holism), epistemology (e.g., realist or constructivist) (Fay, 1996). The transdisciplinary literature therefore excavates underlying assumptions, and requires an understanding of the philosophy of social science. Developing this kind of metaparadigmatic thinking in students is not always an easy task. The increasing focus on hyper-specialization in U.S. education, coupled with a reduced focus on the history of ideas and what used to be thought of as general education, has made it harder for students to understand the underlying matrices of knowledge. The work of developmental psychologist Michael Commons and others suggests that this may be a task of considerable cognitive complexity specific to post-formal thought, one that is not accessible at lower levels of cognitive development (Commons \& Ross, 2008a, 2008b). This is a warning light for transdisciplinarity, suggesting both that it might be misunderstood or in Maruyama's terms, sub-understood (Maruyama, 2004), meaning people are convinced they understand it but they do not, reducing what he refers to a poly-ocularity, or the ability to see one topic from a variety of perspectives, to monocularity.

This brings up a further interesting point for transdisciplinary scholars. It has often been my experience that students initially have difficulty seeing the connection between their own research and examples drawn from other fields. In other words, they struggle to see how a discussion of the unit of analysis with an example drawn from education might apply to their research say in international development. They see the two fields as distinctly different and separate. They do not make the connection. The richness of transdisciplinary literature reviews lies among other things in the way that different perspectives are woven together and how research and insights from different perspectives and different traditions can inform our research. This conceptual/analogical transfer allows us to make distinctions but also appreciate underlying patterns and assumptions. Here is another example therefore of the way that transdisciplinarity requires a complex way of thinking, as I have suggested. This way of thinking also requires a greater focus on the creative aspect of transdisciplinary inquiry. As I have argued elsewhere, education for transdisciplinary work therefore requires complex thinking and creative thinking (Montuori, 2010, 2012; Montuori \& Donnelly, 2013).

\section{Concluding reflections}

What sets transdisciplinarity apart from multi- and inter-disciplinarity is that it is grounded in a fundamental reappraisal and reformulation of the nature of knowledge and inquiry. While considerable steps have been made to articulate the more theoretical dimensions of transdisciplinarity, a new fertile ground is the application of a transdisciplinary approach to education, specifically graduation education, and to very basic dimensions of scholarship such as the literature review. Interweaving dimensions of theory and practice, I have reflected on some of the issues that arise in the process of developing a transdisciplinary literature review, emphasizing in particular the creative/constructive and complexity dimensions of the process. 


\section{References}

Adler, P. (1975). The transitional experience: An alternative view of culture shock. Journal of Humanistic Psychology, 15(4 Fall), 13-23.

Alhadeff-Jones, M. (2008). Three generations of complexity theories: Nuances and ambiguities. Educational Philosophy and Theory, 40(1), 66-82.

Alhadeff-Jones, M. (2010). Challenging the limits of critique in education through Morin's paradigm of complexity. Studies in philosophy and education, 29(5), 477-490.

Banathy, B. H. (1973). Developing a systems view of education : The systems-model approach. Belmont, CA: Siegler/Fearon Publishers.

Barron, F. (1999). All creation is a collaboration. In A. Montuori \& R. Purser (Eds.), Social Creativity (Vol. 1, pp. 49-60). Cresskill, NJ: Hampton.

Becker, E. (1976). The structure of evil. New York: Free Press.

Ceruti, M. (1994). Constraints and possibilities. The evolution of knowledge and knowledge of evolution (A. Montuori, Trans.). New York: Gordon \& Breach.

Commons, M. L., \& Ross, S. N. (2008a). The connection between postformal thought and major scientific innovations. World Futures: The Journal of General Evolution, 64(5), 503-512.

Commons, M. L., \& Ross, S. N. (2008b). What postformal thought is, and why it matters. World Futures: The Journal of General Evolution, 64(5), 321-329.

Descartes, R. (1954). Philosophical writings. London: Open University Press.

Fabbri, D., \& Munari, A. (1984). Strategie del sapere: Verso una psicologia culturale [Strategies of knowledge: Towards a cultural psychology]. Milano: Edizioni Dedalo.

Fabbri, D., \& Munari, A. (1990). Cultural Psychology a new relationship with knowledge. Cultural Dynamics, 3(4), 327-348.

Fay, B. (1996). Contemporary philosophy of social science. A multicultural approach. New York: Blackwell Publishers.

Flyvbjerg, B. (2001). Making social science matter: Why social inquiry fails and how it can succeed again. Cambridge: Cambridge University Press.

Gardner, H. (1994). Creating minds: An anatomy of creativity as seen through the lives of Freud, Einstein, Picasso, Stravinsky, Eliot, Graham, and Gandhi. NewYork: Basic Books.

Gardner, H. (1995). Leading minds. New York: Basic Books.

Glaveanu, V. P. (2010). Paradigms in the study of creativity: Introducing the perspective of cultural psychology. New ideas in psychology, 28, 79-93.

Gordon, L.R. (2006). Disciplinary decadence. Living thought in trying times. Boulder: Paradigm.

Kearney, R. (1999). The narrative imagination. In A. Montuori \& R. Purser (Eds.), Social Creativity. Volume (Vol. 1, pp. 61-79). Cresskill, NJ: Hampton Press.

Maruyama, M. (1974). Paradigmatology and its applications to cross-disciplinary, cross-professional and cross-cultural-communication. Dialectica, 28, 135-196.

Maruyama, M. (2004). Polyocular vision or subunderstanding? Organization, 25(3), 467-480.

Mockros, C.A. , \& Csikszentmhalyi, M. (1999). The social construction of creative lives. In A. Montuori \& R. Purser (Eds.), Social Creativity (Vol. 1, pp. 175-218). Cresskill, NJ: Hampton Press.

Montuori, A. (2005a). Gregory Bateson and the challenge of transdisciplinarity. Cybernetics and Human Knowing, 12(1-2), 147-158(112).

Montuori, A. (2005b). Literature review as creative inquiry. Reframing scholarship as a creative process. Journal of Transformative Education, 3(4), 374-393.

Montuori, A. (2008). Foreword. In B. Nicolescu (Ed.), Transdisciplinarity. Theory and practice (pp. ixxvii). Cresskill, NJ: Hampton Press.

Montuori, A. (2010). Research and the research degree: Transdisciplinarity and Creative Inquiry. In M. Maldonato \& R. Pietrobon (Eds.), Research on scientific research. A transdisciplinary study (pp. 110135). Brighton \& Portland: Sussex Academic Press.

Montuori, A. (2012). Creative Inquiry: Confronting the challenges of scholarship in the $21^{\text {st }}$ century. Futures. The Journal of Policy, Planning and Future Studies, 44(1), 64-70.

Montuori, A., \& Donnelly, G. (2013). Creative Inquiry and scholarship: Applications and implications in a doctoral degree. World Futures, 69(11), 1-19.

Montuori, A., \& Fahim, U. (2004). Cross-cultural encounter as an opportunity for personal growth. Journal of Humanistic Psychology, 44(2), 243-265.

Montuori, A., \& Purser, R. (1999a). Introduction. In A. Montuori \& R. Purser (Eds.), Social creativity (Vol. 1). Cresskill, NJ: Hampton Press.

Montuori, A., \& Purser, R. (Eds.). (1999b). Social Creativity (Vol. 1). Cresskill, NJ: Hampton Press. 
Morin, E. (1991). Le idee: habitat, vita, organizzazione, usi e costumi. [Ideas: Habitat, life, organization, use, and customs.]. Milano: Feltrinelli.

Morin, E. (2008a). On complexity. Cresskill, NJ: Hampton Press.

Morin, E. (2008b). The reform of thought, transdisciplinarity, and the reform of the university. In B. Nicolescu (Ed.), Transdisciplinarity. Theory and practice (pp. 23-32). Cresskill, NJ: Hampton Press.

Morin, E., \& Kern, B. (1999). Homeland Earth: A manifesto for the new millennium. Cresskill, NJ: Hampton Press.

Nicolescu, B. (2002). Manifesto of transdisciplinarity. Albany: SUNY Press.

Robinson, K. (2001). Out of our minds: Learning to be creative. London: Capstone.

Simonton, D. K. (1999). The creative society: Genius vis-a-vis the Zeitgeist. In A. Montuori \& R. Purser (Eds.), Social Creativity (Vol. 1, pp. 237-264). Cresskill, NJ: Hampton Press.

Stigliano, T. (1999). Creativity, Romanticism, and the rise of consumerism. In A. Montuori \& R. Purser (Eds.), Social Creativity (Vol. 1). Cresskill, NJ: Hampton Press.

Wilden, A. (1980). System and structure. Essays in communication and exchange. London: Routledge \& Kegan.

Wilshire, B. (1990). The moral collapse of the university: Professionalism, purity, and alienation. New York: SUNY Press.

\begin{abstract}
About the Author
Alfonso Montuori is an educator, musician, and consultant. His research and publications have focused on the intersection of creativity, culture, and complexity. He has been Distinguished Visiting Professor at Miami University and has also taught at the Central South University in China. He is now Professor at the California Institute of California Institute of Integral Studies.
\end{abstract}

Email: amontuori@ciis.edu

(c) Copyright 2013. The author, ALFONSO MONTUORI, assigns to the University of Alberta and other educational and non-profit institutions a non-exclusive license to use this document for personal use and in courses of instruction provided that the article is used in full and this copyright statement is reproduced. The author also grants a non-exclusive license to the University of Alberta to publish this document in full on the World Wide Web, and for the document to be published on mirrors on the World Wide Web. Any other usage is prohibited without the express permission of the authors. 